\title{
Regulatory Perspectives of Pyrrolizidine Alkaloid Contamination in Herbal Medicinal Products
}

Author

Jacqueline Wiesner

Affiliation

Federal Institute for Drugs and Medical Devices (BfArM), Bonn, Germany

Key words

pyrrolizidine alkaloids, herbal medicinal products, contamination, HMPC

received February 25, 2021

accepted after revision

April 26, 2021

published online

June 24, 2021

Bibliography

Planta Med 2022; 88: 118-124

DOI 10.1055/a-1494-1363

ISSN 0032-0943

(c) 2021. Thieme. All rights reserved.

Georg Thieme Verlag KG, Rüdigerstraße 14,

70469 Stuttgart, Germany

Correspondence

Dr. Jacqueline Wiesner

Federal Institute for Drugs and Medical Devices (BfArM)

K.-G. Kiesinger Allee 3, 53175 Bonn, Germany

Phone: +49(0) 2282075980 , Fax: + 49(0) 2282075395

Jacqueline.wiesner@bfarm.de

\section{ABSTRACT}

The toxicity of plants containing certain pyrrolizidine alkaloids has long been recognized in grazing animals and humans. Genotoxicity and carcinogenicity data from in vitro and in vivo (animal) studies were published over the last few decades for some of the 1,2-unsaturated pyrrolizidine alkaloids, leading to regulatory action on herbal medicinal products with pyrrolizidine alkaloid-containing plants more than 30 years ago. In recent years, it has become evident that in addition to herbal medicinal products containing pyrrolizidine alkaloid-containing plants, these products may also contain pyrrolizidine alkaloids without actually including pyrrolizidine alkaloid-containing plants. This is explained by contamination by accessory herbs (weeds). The national competent authorities of the European member states and the European Medicines Agency, in this case, the Committee on Herbal Medicinal Products, reacted to these findings by setting limits for all herbal medicinal products. This review article will briefly discuss the data leading to the establishment of thresholds and the regulatory developments and consequences, as well as the current discussions and research in this area.

\section{Introduction}

The long-established toxicity of plants containing certain PAs in grazing animals and humans [1], together with genotoxicity and carcinogenicity data from in vitro and in vivo (animal) studies for some of the 1,2-unsaturated PAs from recent decades [2], led to the first regulatory actions for HMPs containing PA-containing plants more than 30 years ago [3].

According to current knowledge, more than 350 different PAs occurring in more than 6000 plants worldwide as mixtures of PAs in different concentrations have been described. They are mostly present in plants as $\mathrm{N}$-oxides [4]. PAs consist of a necine base, and aliphatic mono- or dicarboxylic acids (necic acid). Several PA types can be distinguished based on the chemical structure of the necine base. Furthermore, PAs can occur as mono- or diesters depending on whether 1 or 2 hydroxy groups are esterified [5]; double esterification can lead to macrocyclic diesters [6].
Not all PAs are seen to be toxic. The minimum structural requirements for toxicity of PAs are:

1. A double bond in 1,2 position of a pyrrolizidine moiety;

2. A hydroxymethyl substituent ( $\mathrm{C}-1$ position) in the pyrrolizidine moiety, preferably with a second hydroxyl group in the C-7 position;

3. Esterification of the primary hydroxymethyl group with a branched mono- or dicarboxylic acid containing at least 5 Catoms (necic acid) [7].

\section{Metabolism/Structural Differences of 1,2 Unsaturated PAs}

PAs themselves are not chemically reactive but must rather be regarded as pro-toxins. Bioactivation is necessary for their toxic effects [8]. This occurs mainly in the liver by cytochrome P450 monooxygenases (especially CYP3A and CYP2B) [9]. The toxic 


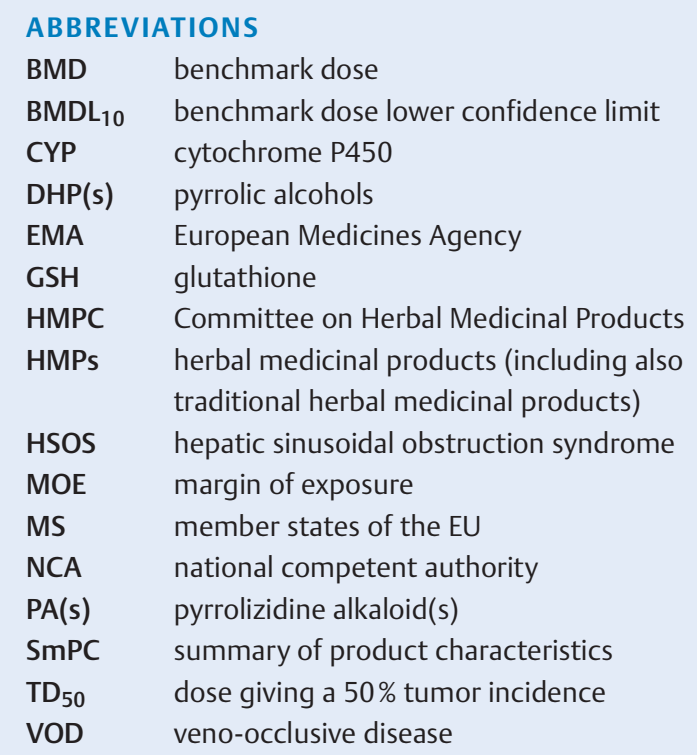

products are dehydropyrrolizidine alkaloids (dehydro-PAs), which are chemically and biologically highly reactive but also short-lived [10], and the less reactive $( \pm)$-6,7-dihydro-7-hydroxy-1-hydroxymethyl-5H-pyrrolizine (DHP) formed by further hydrolysis.

While the short-lived dehydro-PAs mainly damage structures near the site of origin through covalent binding to nucleophilic functional groups in the liver, DHPs are far more persistent and are associated with both extrahepatic damage and tissue adducts that sometimes persist for months or years. Therefore, DHPs are considered the ultimate toxic metabolites [10-12].

The toxicity of PAs is influenced in principle by their structure. In that regard, the structure, the steric hindrance around the necine acid residue, and the lipophilicity influence the formation of adducts [8]. In general, monoesters are considered the least toxic, followed by noncyclic diesters, while cyclic diesters are considered to be the most toxic $[7,13]$.

However, the structure and thus the resulting metabolic pathways and detoxification rates influence the toxicity of PAs but so do many other factors such as species, age, gender or biochemical, physiological, and nutritional status [12]. Since the abundance of CYP enzymes in the human liver varies significantly between individuals, this also could contribute to inter-individual variation in the toxicity of PAs [14].

\section{Toxicity Data and Regulatory Measures in the Field of HMPs}

The toxicity of PA-containing plants to grazing animals has been known for a long time, with the first report of livestock poisoning by PAs dating back to 1787 [1]. From then until today, there have been reports of poisoning in animals from all over the world, for example in Afghanistan, Australia, and Hawaii but also in Europe. While under normal conditions, plants containing PA are probably avoided by grazing animals due to their poor palatability, they are sometimes eaten (e.g., during drought, but also in hay, silage, or pellets or as seeds in cereals) [15]. Cases of poisoning have been described in many animal species, including cattle, sheep, chickens, ducks, pigs, and horses $[1,9,16]$. Acutely intoxicated animals show signs of liver failure including neurological signs such as depression and opisthotonos. Gross and histologic changes are mainly described with panlobular hepatocellular necrosis accompanied by hemorrhage with minimal inflammation [12,17]. Studies in laboratory animals have concluded that even a single dose of PA can lead to advanced chronic liver disease and cirrhosis [18].

Strong species-specific toxicity linked to a species-specific activating and inactivating metabolic pathway has been reported from studies in farm and laboratory animals. Rats, mice, pigs, horses, and cows are considered very sensitive to PA intoxication, while sheep, goats, and rabbits are described as less sensitive [1921].

\section{Acute/Chronic Toxicity in Humans}

First reports about acute poisonings in humans date from the beginning of the last century, and in more recent times cases are still reported from time to time [8]. Most reports about larger outbreaks (thousands of people affected) result from developing countries while single cases are also reported from developed countries $[1,8]$.

Knowledge about PA intake via food increased during recent decades. This applied mainly to grain but also foods of animal origin (such as milk, eggs, honey) or other material, for instance, packed lettuce boxes [1]. Some PA-containing herbs are used as a spice or for medicinal purposes, such as Borago officinalis or Symphytum officinale. It has been postulated that after dietary exposure to PAs, in vivo alkylation continues until the reservoir of labile tissue-bound adducts is eliminated. This occurs mainly via soluble conjugates (e.g., with GSH) in urine and bile. This can take many months so that even a single exposure to PAs continues to cause silent progressive chronic disease, which is then unlikely to be caused by PAs in the diet [10].

PA poisoning is usually manifested as acute VOD characterized by a dull dragging ache in the right upper abdomen and rapidly filling ascites, and sometimes also is associated with oliguria, swelling feet, and massive pleural effusion [22]. It includes centrilobular hemorrhagic necrosis and hepatomegaly with accompanying ascites [22]. The mortality rate of VOD is approx. 50\% [23]. In some cases, it has been described that a single episode of acute disease can progress to cirrhosis in a relatively short time despite treatment $[24,25]$. In this context, tissue-bound DHP adducts are considered to be the source of ongoing alkylation [26].

Less severe cases may show clinical or even apparent recovery before cirrhosis and liver failure may develop years later. Others may develop subacute pathological changes in the liver that either regress or lead to cirrhosis and liver failure [11]. Liver-damaging agents (e.g., viruses, bacterial endotoxins, aflatoxins, and environmental copper) can exacerbate the liver damage and cancers caused by PAs [18,27]. Moreover, although all age groups can be affected by PA poisoning, children are particularly vulnerable to the effects of PAs [10]. 
In addition, it is also considered possible for toxic lung disease to develop. It has been postulated that sporadic small doses of PAs over a prolonged period are more likely to cause cancer and pulmonary hypertension than liver damage [10]. Meanwhile, pyrrole protein adducts have been detected in the blood of patients diagnosed with HSOS and documented to have ingested PA-containing herbs [8].

\section{Genotoxicity and Carcinogenicity of PAs}

\section{Genotoxicity}

The potential genotoxicity of PAs (or rather their active metabolites) has been recognized for many years. The genotoxic effects described for several PAs include mutations, sister chromatid exchanges, and chromosomal aberrations, respectively [28-30]. Furthermore, for some PAs, induction of micronuclei formation in erythrocytes in the bone marrow and fetal liver in mice has been shown [18]. Chromosomal aberrations have also been demonstrated in rats and humans with VOD [31]. It was discussed, at least for riddelliine, that DNA-adduct formation may play a role in the genotoxicity [32].

From the available experimental data, it is evident that, in general, both PA metabolites (dehydro-PA and DHP) can lead to similar alkylation products. For the antimitotic effect that then follows, a simultaneous or temporally subsequent stimulus for cell division must be present. Such a stimulus may be provided by the acute necrotic action of the primary dehydro-PA metabolite or by any other cause of acute liver injury leading to tissue regeneration. In very young animals, the stimulus may be the increased replication rate already present in them [18].

\section{Carcinogenicity}

The first studies on the carcinogenicity of individual PAs were conducted in the 1950s. Since then-especially in the 1970s-several additional studies have been carried out that have substantiated the link to the carcinogenic properties of PAs. In experimental rodents, PAs were found to induce mainly liver tumors [2]. Until now, more than 20 purified PAs, PA-metabolites, or plant extracts containing PAs have been demonstrated to induce tumors in rodents [9]. It should be noted that the carcinogenic activity of PAs appears to parallel their mutagenic behavior [33] but not their hepatotoxicity. Therefore, it is necessary to distinguish in the (regulatory) references exactly which of the endpoints are referenced by the measures/statements. It is mostly only referred to as "toxicity", although current studies and regulations in Europe mainly refer to the carcinogenic effects, as these can be triggered already with much lower exposures to PAs. In rats, appropriately low, repeated doses of several alkaloids have been shown to induce tumors but even a single dose has been shown to be carcinogenic. For example, a single dose of lasiocarpine [34] induced changes in the liver after approximately 13 months that were observed in a similar form in the earlier stages of liver carcinogenesis by various PAs after multiple doses.

It should be noted that by comparing total intake levels (human toxicity and total doses in long-term studies in rats), it could be inferred that humans are more sensitive; this suggests that hu- mans may survive sufficiently long to develop cancer after only a brief exposure at this amount or a longer exposure at a much lower amount $[2,18]$.

Later, 2 carcinogenicity studies were performed that are close to the current requirements for such studies and are currently the basis for deriving limits. In a 2-year feeding study of lasiocarpine (24 rats per sex in each treatment group), lasiocarpine was shown to be carcinogenic under the conditions of this bioassay in Fischer 344 rats, producing hepatocellular tumors and angiosarcomas of the liver in both sexes and hematopoietic tumors in females [35]. In this study, 3 dose groups and female and male animals were used, although the group size was quite small (24/sex). No animal of the highest dose groups $(1.5 \mathrm{mg} / \mathrm{kg}$ b.w./day) survived. Regarding the endpoint of dose-depending hemangiosarcoma of the liver (male animals), a BMDL 10 of $73 \mu \mathrm{g} / \mathrm{kg}$ b.w./day was derived [4].

In another 2-year study, riddelliine was shown to induce liver hemangiosarcomas, hepatocellular adenomas, and carcinomas in both male and female rats and lung alveolar adenomas in female mice [36]. In this gavage study (50 animals/sex each), 5 dose groups in females and 1 dose group in males were used (highest dose group only $=1 \mathrm{mg} / \mathrm{kg} /$ day; averaged $0.714 \mathrm{mg} / \mathrm{kg} /$ day). High mortality occurred in the highest dose group (only 3 male animals survived, while no female animals survived). Although $\mathrm{BMDL}_{10}$ values ranging from 0.180 to $0.299 \mathrm{mg} / \mathrm{kg}$ b. w. per day (female animals) could be calculated, for the calculation of the $\mathrm{BMDL}_{10}$ of $70 \mu \mathrm{g} / \mathrm{kg}$ b. w. per day, the male rat data of the lasiocarpine study was selected as the reference point for the MOE calculation [4].

\section{Pharmaceutical Regulation Concerning PA-containing Plants}

As early as the late 1980s, based on the findings at that time on the toxicity and carcinogenicity of PAs, the German Federal Health Agency (BGA) initiated a graduated plan procedure on PA-containing plants used for medicinal purposes.

According to the German Medicinal Act, a graduated plan is aimed at preventing direct or indirect hazards to human and animal health from medicinal products. In this context, the obligations of the competent higher federal authority (formerly BGA, today BfArM or PEI) are to record and evaluate risks occurring during the administration of medicinal products and to coordinate the measures to be adopted. In most cases, it starts with adverse effects being reported to the NCAs from reports and/or other information (e.g., expert opinions, studies). This triggers an exchange of information between the NCA(s) and concerned pharmaceutical entrepreneur(s) (level I). If based on this information, a direct or indirect risk to human health is suspected (and the pharmaceutical entrepreneur has not himself taken the necessary risk reduction measures), advice on the necessary risk reduction measures is required (level II). On that, the pharmaceutical entrepreneur(s) will be heard. Either the suspicion can be refuted by the submission of documents, which leads to a discontinuation of the graduated plan, or, if the suspicion cannot be refuted, riskminimizing measures are ordered. These can be either the inclu- 
sion of appropriate warnings, contraindications, and side effects in the product information and SmPC or measures such as a withdrawal from the market [37].

In 1992, a graduated plan procedure concerning PAs was finalized by setting in force the graduated plan concerning medicinal products containing PAs with a necine system unsaturated in 1,2 position. The maximum daily dose of such PAs for internal use was set at $1 \mu \mathrm{g}$ for a maximum duration of 6 weeks per year and $0.1 \mu \mathrm{g}$ without any limitation in the duration. The maximal daily dose of PAs in the case of cutaneous application is $100 \mu \mathrm{g}$ for a maximum duration of 6 weeks per year and $10 \mu \mathrm{g}$ without any limitation in the duration of use [3].

With the adoption of Directive 2004/24/EU, the Committee on Herbal Medicinal Products (HMPC) was established at the European Medicines Agency (EMA). The tasks of the HMPC include the preparation of monographs that summarize the data on the efficacy and safety of herbal substances or herbal preparations after critical evaluation. They thus reflect the current state of knowledge. In the case of questions (e.g., on toxicologically relevant constituents of herbal substances or preparations), the HMPC prepares supporting documents as so-called "Public Statements" (PS), as was necessary, for example, in the preparation of the monograph on Symphytum officinalis for the evaluation of the toxicity of PAs.

In 2014, a "Public statement on the use of herbal medicinal products containing toxic, unsaturated pyrrolizidine alkaloids (PAs)" (EMA/HMPC/893 108/2011) was published [38]. The available data on PAs were assessed, and a limit for the acceptable daily intake of $0.35 \mu \mathrm{g} /$ day was defined for adults.

When evaluating the studies on lasiocarpine and riddelliine, the HMPC reached the same conclusions as EFSA (2011) regarding the suitability of the studies to derive limits. The published daily limit of $0.35 \mu \mathrm{g} /$ day was derived by transferring the calculation of the lasiocarpine $\mathrm{BMDL}_{10}$ of EFSA [4] to the approach of the ICH M7 Guideline (EMA/CHMP/ICH/83812/2013). According to this Guideline, for pharmaceutical products, the calculation of the acceptable lifelong intake of genotoxic carcinogens can be performed either by using the $\mathrm{TD}_{50^{-}}$or $\mathrm{BMDL}_{10}$-based approach. Since both approaches lead to almost identical limits for lasiocarpine $\left(\mathrm{TD}_{50}=0.39 \mu \mathrm{g} /\right.$ day; $\mathrm{BMDL}_{10}=0.35 \mu \mathrm{g} /$ day $)$, the use of the $\mathrm{BMDL}_{10}$ approach was considered acceptable.

Already in 2013, the first reports on contamination of HMPs with PA-containing herbs were reported. Based on this, the NCA (e.g., in Germany) asked the industry to collect data. From the data provided and the investigations initiated thereafter, it could be assumed that the content of PAs was due to contamination with so-called accessory herbs, such as the Heliotropium or Senecio species, which enter the respective batches during harvesting. Since under certain circumstances, the content of PAs can result from contamination with very few plants, a timely solution to the contamination problem was not possible with agricultural measures alone, but in particular, made increased control necessary [39]. Consequently, after intensive discussions both with the industry associations but also at the European level, BfArM was the first European NCA to publish a notice on March 1, 2016, introducing a maximum limit of $1.0 \mu \mathrm{g}$ PA daily for all HMPs as a transitional measure [40]. Later, it was clarified by BfArM, that the tran- sitional period is not expected to last longer than 3 years and that thereafter the limit value would be in accordance with the existing HMPC assessment of $0.35 \mu \mathrm{g} /$ day [41].

However, other European NCAs have also addressed the issue of PA contamination in HMPs. A short time later, in May 2016, the HMPC published another PS with transitional recommendations for risk management and quality control [41]. A contamination level of HMPs that would lead to a maximum daily intake of $1.0 \mu \mathrm{g}$ of PAs per day during a transitional period of 3 years (which was then extended for another 2 years to allow for a time a final evaluation in the context of the new publications on PAs) was again considered acceptable from a public health perspective. During this period, manufacturers of HMPs would be required to take the necessary measures to reduce contamination to a level leading to a daily intake of no more than $0.35 \mu \mathrm{g}$ PAs per day [41, 42].

The revision of the PS of the HMPC is currently ongoing to revise the transitional recommendations.

\section{Further Developments}

In the years after the publication of the 2 PS of the HMPC (2014 and 2016), many discussions, publications, investigations, and regulations took place. Several issues have been raised that are relevant to the safety assessment of PAs, and these are mentioned here as examples.

The detection and determination of PA levels due to contamination by accessory herbs require highly sensitive methods in the field of trace analysis. Up to now, there have been no official test methods for this purpose, even though the first studies on this subject took place very early on nationally, see BfR (2014) [43]. The HMPC has therefore requested that the European Pharmacopoeia (Ph. Eur.) consider the development of an appropriate analytical method validation for PAs in HMPs as a matter of priority. An expert group was founded at the European Directorate for the Quality of Medicines (EDQM) in September 2017, and at its 168th session in November 2020, the European Pharmacopoeia Commission adopted the new general chapter "Contaminant pyrrolizidine alkaloids (2.8.26)" [44]. This also specifies the PAs that must be quantified as a minimum ( $\bullet$ Table 1 ).

In 2017, EFSA updated its opinion on toxic unsaturated PAs [45] due to the revision of the Guideline "Use of benchmark dose approach in risk assessment" [46]. This recommended model averaging as the preferred method for calculating the BMD confidence interval while acknowledging that the relevant tools are still under development and may not be readily available to all. Using the modified evaluation method, the evaluation of the data sets on lasiocarpine [35] and riddelliine [36] showed that better evaluation intervals were now obtained for riddelliine, despite the still relatively high uncertainty related to the insufficient information on the dose-response relationship of the study, as only the highest tested dose induced a statistically significant increase in tumor incidence. However, the study design as such is seen to be particularly suitable for the performance of BMD modeling. In addition, using model averaging, a partial overlap of the $\mathrm{BMD}_{10}$ upper and lower confidence intervals calculated was observed for both studies. This was more evident when a benchmark response falling 
- Table 1 PAs that must be quantified as a minimum based on the requirements of Ph.Eur [44].

\begin{tabular}{|c|c|}
\hline 1. & Echimidine \\
\hline 2. & Echimidine-N-oxide \\
\hline 3. & Erucifoline \\
\hline 4. & Erucifoline- $\mathrm{N}$-oxide \\
\hline 5. & Europine \\
\hline 6. & Europine-N-oxide \\
\hline 7. & Heliotrine \\
\hline 8. & Heliotrine-N-oxide \\
\hline 9. & Intermedine \\
\hline 10. & Intermedine-N-oxide \\
\hline 11. & Jacobine \\
\hline 12. & Jacobine-N-oxide \\
\hline 13. & Lasiocarpine \\
\hline 14. & Lasiocarpine-N-oxide \\
\hline 15. & Lycopsamine \\
\hline 16. & Lycopsamine-N-oxide \\
\hline 17. & Monocrotaline \\
\hline 18. & Monocrotaline-N-oxide \\
\hline 19. & Retrorsine \\
\hline 20. & Retrorsine-N-oxide \\
\hline 21. & Senecionine \\
\hline 22. & Senecionine-N-oxide \\
\hline 23. & Seneciphylline \\
\hline 24. & Seneciphylline-N-oxide \\
\hline 25. & Senecivernine \\
\hline 26. & Senecivernine- $\mathrm{N}$-oxide \\
\hline 27. & Senkirkine \\
\hline 28. & Trichodesmine \\
\hline
\end{tabular}

within the tested dose ranges for both substances was selected, such as $30 \%$. So, the results were interpreted to imply that the 2 substances may have similar carcinogenic potency. As a result, EFSA selected the BMDL 10 of $237 \mu \mathrm{g} / \mathrm{kg}$ b.w. per day, derived for the incidence of hepatic hemangiosarcoma in female rats exposed to riddelliine, as the RP for the chronic risk assessment of PAs [45]. This $\mathrm{BMDL}_{10}$ is approximately 3 times the previous $\mathrm{BMDL}_{10}$ derived from the lasiocarpine study.

It has also been discussed for many years whether, due to the presumed different toxicities, different limits for individual PAs should be defined instead of the limit based on 1 compound. Variations in the number of ester substitutions, lipophilicity, and steric hindrance of the necine acid groups can significantly affect the rate of metabolic activation and thus toxicity [47]. For instance, among 9 retronecine-type PAs tested, the open-ring diester showed the highest efficiency for pyrrole-protein adduct formation, followed by the 12-membered macrocyclic diester and then by the 11-membered macrocyclic diester, while the monoester showed the lowest efficiencies [47].

Based on considerations of structure, kinetic considerations, in vitro studies, or some in vivo tests in different animal species on different PAs or a combination of them, concepts of potency factors were presented or their possibilities were considered to evaluate the possible effects of combined exposure (e.g. [48-53]).

However, it has also been repeatedly pointed out that data on carcinogenicity would be preferentially needed for the comparison of potency and that the data available to date would not be sufficient to adequately define the different potencies $[45,54]$. However, the importance of toxicogenetics/biokinetics data has also been noted to develop a robust understanding (especially also because carcinogenicity data for all PAs should be considered highly unlikely) of the relative potencies for a realistic risk assessment of PA mixtures [50,53,55].

Furthermore, the inter-individual differences and the importance of other etiologic factors, such as alcohol abuse, for example, were discussed, and the importance of such questions in the context of data evaluation was discussed [23].

Other points of discussion include the transferability of data from carcinogenicity studies to humans. Liver hemangiosarcoma was derived from animal studies as a key effect. However, the incidence of liver hemangiosarcoma in humans is reported to be very low. This is also because PA intake from food/herbal medicines should actually have remained constant over the last decades. This naturally leads to considerations of whether PA intake in humans would lead to different forms of neoplasms than in rodents [41].

If one assumes a low, intermittent dietary exposure to toxic unsaturated PAs, slow progressive chronic diseases such as cancer, cirrhosis, and pulmonary hypertension could be possible consequences, without hepatotoxicity being in the foreground or without a direct link to the intake being possible due to the long periods involved. Other factors, such as a family predisposition to the toxicity of PAs or also the diet (e.g., the intake of other potentially liver-damaging compounds or also so-called antimutagenic compounds from food plants) must also be taken into account and make a conclusive assessment more difficult [56].

\section{Conclusion}

Because of the known involvement of PAs in human poisoning and their potential carcinogenicity, exposure to toxic unsaturated PAs should be kept as low as practically possible $[18,57]$.

This must also be taken into account in the risk-benefit assessment of medicinal products, especially if the PA input is caused by accessory herbs (i.e., contamination). When the problem became known, in addition to regulatory measures by the NCA or the HMPC, attempts were also made by the industry to reduce the PA input through such contamination.

In this context, a data collection on the batches of medicinal plants/extracts used was initiated first, but in addition, the German HMP industry also initiated measures to avoid and/or reduce PA contamination. For example, in addition to root cause research projects, a Code of Practice (CoP) has been developed together 
with herb growers to identify potential risks for each process step along the entire process chain (e.g., cultivation, harvesting, incoming goods inspection, drug processing up to the release of the finished drug product) $[58,59]$.

From the previous studies, it became clear that complete elimination of PA contamination seems to be impossible, especially when it is realized that already very small amounts of PA-containing plants, such as 1 Senecio plant per hectare in a crop of St. John's wort (Hyperici herba), would be sufficient to exceed the threshold recommended by the HMPC. However, previous measures have already achieved a significant reduction in the total PA load of HMPs [60].

At the same time, maximum levels for PAs in various food categories (e.g., tea, herbal teas, food supplements, and honey) are being introduced in the food sector [61].

In the coming years, the main task will be to expand the knowledge of the different toxicity/carcinogenicity of the individual PAs or PA groups, so that, for example, a differentiated view will be possible through the regulatory-approved definition of relative potency factors. This will involve avoiding overestimation or underestimation of risk. For this purpose, since a general testing of all (or at least several) PAs in classical carcinogenicity studies must also be excluded for animal welfare reasons, discussion on the correct endpoints of the in vitro/in vivo tests to be used, including kinetic considerations, will be necessary. This requires close cooperation between research (universities, industry) and regulatory authorities to ensure the development and subsequent acceptance of such models.

\section{Contributors' Statement}

Data collection: J. Wiesner; analysis and interpretation of the data: J. Wiesner; drafting the manuscript: J. Wiesner; critical revision of the manuscript: J. Wiesner.

\section{Conflict of Interest}

The authors declare that they have no conflict of interest.

\section{References}

[1] Molyneux RJ, Gardner DL, Colegate SM, Edgar JA. Pyrrolizidine alkaloid toxicity in livestock: a paradigm for human poisoning? Food Addit Contam Part A Chem Anal Control Expo Risk Assess 2011; 28: 293-307

[2] Culvenor CC. Estimated intakes of pyrrolizidine alkaloids by humans. A comparison with dose rates causing tumors in rats. J Toxicol Environ Health 1983; 11: 625-635

[3] Bundesgesundheitsamt. Bekanntmachung über die Zulassung und Registrierung von Arzneimitteln vom 05. Juni 1992 Abwehr von Arzneimitteln-Stufe II, hier: Arzneimittel, die Pyrrolizidin-Alkaloide mit einem 1,2ungesättigtem Necin-Gerüst enthalten. BAnz 1992; 111: 4805

[4] EFSA. Scientific opinion on pyrrolizidine alkaloids in food and feed. EFSA Panel on Contaminants in the Food Chain (CONTAM). EFSA J 2011; 9: 2406

[5] These A, Bodi D, Ronczka S, Lahrssen-Wiederholt M, Preiss-Weigert A. Structural screening by multiple reaction monitoring as a new approach for tandem mass spectrometry: presented for the determination of pyrrolizidine alkaloids in plants. Anal Bioanal Chem 2013; 405: 9375-9383

[6] Roeder E. Medicinal plants in China containing pyrrolizidine alkaloids. Pharmazie 2000; 55: 711-726
[7] Teuscher E, Lindequist U. Biogene Gifte. Biologie-Chemie-Pharmakologie. Stuttgart, Jena, New York: Gustav Fischer; 1994

[8] Ma J, Xia Q, Fu PP, Lin G. Pyrrole-protein adducts-a biomarker of pyrrolizidine alkaloid-induced hepatotoxicity. J Food Drug Anal 2018; 26: $965-$ 972

[9] Fu PP. Pyrrolizidine alkaloids: metabolic activation pathways leading to liver tumor initiation. Chem Res Toxicol 2017; 30: 81-93

[10] Edgar JA, Colegate SM, Boppré M, Molyneux RJ. Pyrrolizidine alkaloids in food: a spectrum of potential health consequences. Food Addit Contam Part A Chem Anal Control Expo Risk Assess 2011; 28: 308-324

[11] Food Standards Australia New Zealand (FSANZ). Pyrrolizidine Alkaloids in Food. A toxicological Review and Risk Assessment. Australia New Zealand Technical Report Series No. 2. [Epub 2001 November]. Canberra, Wellington: Australia New Zealand Food Authority; 2001. Accessed June 16, 2021 at: https://www.foodstandards.gov.au/publications/ documents/TR2.pdf

[12] Stegelmeier BL, Colegate SM, Brown AW. Dehydropyrrolizidine alkaloid toxicity, cytotoxicity, and carcinogenicity. Toxins (Basel) 2016; 8: 356

[13] Moreira R, Pereira DM, Valentão P, Andrade PB. Pyrrolizidine alkaloids: chemistry, pharmacology, toxicology and food safety. Int J Mol Sci 2018; 19: 1668

[14] Ning ], Chen L, Strikwold M, Louisse J, Wesseling S, Rietjens IMCM. Use of an in vitro-in silico testing strategy to predict inter-species and inter-ethnic human differences in liver toxicity of the pyrrolizidine alkaloids lasiocarpine and riddelliine. Arch Toxicol 2019; 93: 801-818

[15] Stegelmeier BL, Edgar JA, Colegate SM, Gardner DR, Schoch TK, Coulombe RA, Molyneaux RJ. Pyrrolizidine alkaloid plants, metabolism and toxicity. J Natural Toxins 1999; 8: 95-116

[16] Petzinger E. Pyrrolizidine alkaloids and seneciosis in farm animals. Part 1: occurrence, chemistry and toxicology. Tierarztl Prax Ausg G Grosstiere Nutztiere 2011; 39: 221-230

[17] Preliasco M, Gardner D, Moraes J, González AC, Uriarte G, Rivero R. Senecio grisebachii Baker: pyrrolizidine alkaloids and experimental poisoning in calves. Toxicon 2017; 133: 68-73

[18] WHO. International Programme on Chemical Safety (IPCS). Pyrrolizidine Alkaloids. Environmental Health Criteria 80. Geneva: WHO; 1988

[19] Fashe MM, Juvonen RO, Petsalo A, Räsänen J, Pasanen M. Species-specific differences in the in vitro metabolism of lasiocarpine. Chem Res Toxicol 2015; 28: 2034-2044

[20] Kolrep F, Numata J, Kneuer C, Preiss-Weigert A, Lahrssen-Wiederholt M, Schrenk D, These A. In vitro biotransformation of pyrrolizidine alkaloids in different species. Part I: Microsomal degradation. Arch Toxicol 2018; 92: 1089-1097

[21] Xia Q, He X, Shi Q, Lin G, Fu PP. Quantitation of DNA reactive pyrrolic metabolites of senecionine-A carcinogenic pyrrolizidine alkaloid by $\mathrm{LC} /$ MS/MS analysis. J Food Drug Anal 2020; 28: 167-174

[22] Prakash AS, Pereira TN, Reilly PE, Seawright AA. Pyrrolizidine alkaloids in human diet. Mutat Res 1999; 443: 53-67

[23] Stickel F, Seitz HK. The efficacy and safety of comfrey. Public Health Nutr 2000; 3: 501-508

[24] Tandon HD, Tandon BN, Tandon R, Nayak NC. A pathological study of the liver in an epidemic outbreak of veno-occlusive disease. Indian J Med Res 1977; 65: 679-684

[25] Stuart KL, Bras G. Veno-occlusive disease of the liver. Q J Med 1957; 26 291-315

[26] Mattocks AR. Chemistry and Toxicology of Pyrrolizidine Alkaloids. London, New York: Academic Press; 1986

[27] Yee SB, Kinser S, Hill DA, Barton CC, Hotchkiss JA, Harkema JR, Ganey PE, Roth RA. Synergistic hepatotoxicity from coexposure to bacterial endotoxin and the pyrrolizidine alkaloid monocrotaline. Toxicol Appl Pharmacol 2000; 166: 173-185 
[28] Kraus C, Abel G, Schimmer O. Studies on the chromosome damaging effect of some pyrrolizidine alkaloids in human lymphocytes in vitro. Planta Med 1985; 51: 89-91

[29] Fu PP, Xia Q, Lin G, Chou MW. Pyrrolizidine alkaloids-genotoxicity, metabolism enzymes, metabolic activation, and mechanisms. Drug Metab Rev 2004; 36: 1-55

[30] Mei N, Guo L, Fu PP, Fuscoe JC, Luan Y, Chen T. Metabolism, genotoxicity, and carcinogenicity of comfrey. J Toxicol Environ Health B Crit Rev 2010; 13: 509-526

[31] Martin PA, Thorburn M], Hutchinson S, Bras G, Miller CG. Preliminary findings of chromosomal studies on rats and humans with veno-occlusive disease. $\mathrm{Br}$ J Exp Pathol 1972; 53: 374-380

[32] Mei N, Guo L, Liu R, Fuscoe JC, Chen T. Gene expression changes induced by the tumorigenic pyrrolizidine alkaloid riddelliine in liver of Big Blue rats. BMC Bioinformatics 2007; 8: S4

[33] Hartwig A, Arand M, Epe B, Guth S, Jahnke G, Lampen A, Martus H], Monien B, Rietjens IMCM, Schmitz-Spanke S, Schriever-Schwemmer G, Steinberg P, Eisenbrand G. Mode of action-based risk assessment of genotoxic carcinogens. Arch Toxicol 2020; 94: 1787-1877

[34] Schoental R, Magee PN. Chronic liver changes in rats after a single dose of lasiocarpine, a pyrrolizidine (Senecio) alkaloid. J Pathol Bacteriol 1957; 74: 305-319

[35] NTP. Bioassay of lasiocarpine for possible carcinogenicity. Technical report series No. 39, 1978. Accessed June 16, 2021 at: http://ntp.niehs. nih.gov/ntp/htdocs/lt_rpts/tr039.pdf

[36] National Toxicology Program. Final report on carcinogens-background document for riddelliine. Rep Carcinog Backgr Doc 2008; (8-5977): i-104

[37] Ernst M, Thiele A, Kroth E. Fast 35 Jahre Stufenplanverfahren in Deutschland. Pharm Ind 2014; 76: 1010-1015

[38] EMA. Public statement on the use of herbal medicinal products containing toxic, unsaturated pyrrolizidine alkaloids (PAs). EMA/HMPC/893108/ 2011. 24 November 2014. Accessed June 16, 2021 at: http://www.ema. europa.eu/docs/en_GB/document_library/Public_statement/2014/12/ WC500179559.pdf

[39] BfArM. Verunreinigung pflanzlicher Arzneimittel durch Pyrrolizidinalkaloide: BfArM macht der pharmazeutischen Industrie neue Vorgaben. Pressemitteilung Nr 4/16 from 01.03.2016. Accessed June 16, 2021 at: https://www.bfarm.de/SharedDocs/Pressemitteilungen/DE/2016/pm42016.html

[40] BfArM. Bekanntmachung zur Prüfung des Gehalts an Pyrrolizidinalkaloiden zur Sicherstellung der Qualität und Unbedenklichkeit von Arzneimitteln, die pflanzliche Stoffe bzw. pflanzliche Zubereitungen oder homöopathische Zubereitungen aus pflanzlichen Ausgangsstoffen als Wirkstoffe enthalten 01.03.2016. Accessed June 16, 2021 at: https://www.bfarm. de/DE/Arzneimittel/Arzneimittelzulassung/Zulassungsarten/Besondere Therapierichtungen/Allgemeines/_node.htm

[41] EMA. Public statement on contamination of herbal medicinal products/ traditional herbal medicinal products with pyrrolizidine alkaloids. EMA/ HMPC/328782/2016. 2016. 31 May 2016. Accessed June 16, 2021 at: https://www.ema.europa.eu/documents/public-statement/publicstatement-contamination-herbal-medicinal-products/traditionalherbal-medicinal-products-pyrrolizidine-alkaloids_en.pdf

[42] EMA. HMPC meeting report on European Union herbal monographs, guidelines and other activities. 16 January 2019. Accessed June 16, 2021 at: https:/www.ema.europa.eu/en/events/committee-herbalmedicinal-products-hmpc-14-16-january-2019

[43] BfR. Determination of pyrrolizidine alkaloids (PA) in botanical substances using SPE-LC-MS/MS. Description of the Method. 2014. Accessed June 16, 2021 at: https://www.bfr.bund.de/cm/349/determination-ofpyrrolizidine-alkaloids-pa-in-plant-material.pdf

[44] Council of Europe. European Pharmacopoeia Commission adopts new general chapter Contaminant pyrrolizidine alkaloids (2.8.26). 05 January 2021. Accessed June 16, 2021 at: https://www.edqm.eu/en/news/ european-pharmacopoeia-commission-adopts-new-general-chaptercontaminant-pyrrolizidine

[45] EFSA. Risks for human health related to the presence of pyrrolizidine alkaloids in honey, tea, herbal infusions and food supplements. EFSA EFSA CONTAM Panel (Panel on Contaminants in the Food Chain). EFSA J 2017; 15: 4908

[46] EFSA. Update: guidance on the use of the benchmark dose approach in risk assessment. EFSA Scientific Committee. EFSA J 2017; 15: 4658

[47] Ruan J, Yang M, Fu P, Ye Y, Lin G. Metabolic activation of pyrrolizidine alkaloids: insights into the structural and enzymatic basis. Chem Res Toxicol 2014; 27: 1030-1039

[48] Merz KH, Schrenk D. Interim relative potency factors for the toxicological risk assessment of pyrrolizidine alkaloids in food and herbal medicine. Toxicol Lett 2016; 263: 44-57

[49] Chen L, Mulder PP], Louisse ], Peijnenburg A, Wesseling S, Rietjens IMCM. Risk assessment for pyrrolizidine alkaloids detected in (herbal) teas and plant food supplements. Regul Toxicol Pharmacol 2017; 86: 292-302

[50] Allemang A, Mahony C, Lester C, Pfuhler S. Relative potency of fifteen pyrrolizidine alkaloids to induce DNA damage as measured by micronucleus induction in HepaRG human liver cells. Food Chem Toxicol 2018; 121: $72-81$

[51] Louisse J, Rijkers D, Stoopen G, Holleboom W], Delagrange M, Molthof E, Mulder PPJ, Hoogenboom RLAP, Audebert M, Peijnenburg AACM. Determination of genotoxic potencies of pyrrolizidine alkaloids in HepaRG cells using the $\mathrm{yH} 2 \mathrm{AX}$ assay. Food Chem Toxicol 2019; 131: 110532

[52] Chen L, Peijnenburg A, de Haan L, Rietjens IMCM. Prediction of in vivo genotoxicity of lasiocarpine and riddelliine in rat liver using a combined in vitro-physiologically based kinetic modeling-facilitated reverse dosimetry approach. Arch Toxicol 2019; 93: 2385-2395

[53] Lester C, Troutman J, Obringer C, Wehmeyer K, Stoffolano P, Karb M, Xu Y, Roe A, Carr G, Blackburn K, Mahony C. Intrinsic relative potency of a series of pyrrolizidine alkaloids characterized by rate and extent of metabolism. Food Chem Toxicol 2019; 131: 110523

[54] FAO/WHO (Joint FAO/WHO Expert Committee on Food Additives). Evaluation of certain food additives and contaminants. Eightieth report of the Joint FAO/WHO Expert Committee on Food Additives. (WHO technical report series; no. 995, 2016). Accessed June 16, 2021 at: https:// apps.who.int/iris/handle/10665/204410

[55] Ning J, Chen L, Rietjens IMCM. Role of toxicokinetics and alternative testing strategies in pyrrolizidine alkaloid toxicity and risk assessment; stateof-the-art and future perspectives. Food Chem Toxicol 2019; 131: 110572

[56] Ferguson LR, Philpott M. Nutrition and mutagenesis. Annu Rev Nutr 2008; 28: 313-329

[57] EFSA. Opinion of the scientific panel on contaminants in the food chain on a request from the European Commission related to pyrrolizidine alkaloids as undesirable substances in animal feed (Question $N^{\circ}$ EFSA-Q-2003-065). EFSA J 2007; 447: 1-51

[58] $\mathrm{BAH}$. Code of Practice to prevent and reduce pyrrolizidine alkaloid contaminations of medicinal products of plant origin. 29 April 2016. Accessed June 16, 2021 at: https://www.journals.elsevier.com/journalof-applied-research-on-medicinal-and-aromatic-plants/news/code-ofpractice-to-prevent-and-reduce-pyrrolizidine-alkaloi

[59] Dittrich H, Hösel K, Sievers H, Klier B, Waimer F, Heuberger H, Plescher A, Armbrüster N, Steinhoff B. Code of Practice zur Vermeidung und Verringerung von Kontaminationen pflanzlicher Arzneimittel mit Pyrrolizidinalkaloiden. Pharm Ind 2016; 78: 836-845

[60] Steinhoff B. Pyrrolizidine alkaloid contamination in herbal medicinal products: Limits and occurrence. Food Chem Toxicol 2019; 130: 262-266

[61] European Commission. Commission Regulation (EU) 2020/2040 of December 2020 amending Regulation (EC) No 1881/2006 as regards maximum levels of pyrrolizidine alkaloids in certain food stuffs. OJEU 2020; 63: L420 